\title{
Strategi Diversifikasi Atraksi Budaya Dalam Mendukung Pengembangan Wisata Desa Wakatobi
}

\author{
${ }^{1}$ Muhadjir Suni, ${ }^{2}$ Muh. Zainuddin Badollahi \\ ${ }^{12}$ Politeknik Pariwisata Makassar \\ Makassar, Indonesia, 90224 \\ E-mail: muhadjirsuni@yahoo.com ; muhammadzainuddinb@gmail.com \\ Received: 11 Maret 2020; Revised: 09 April 2020; Accepted: 29 April 2020
}

\begin{abstract}
This study aims to determine and analyze the Diversification Strategy of Cultural Attractions in Support of Tourism Development in Wakatobi Village. This research method is qualitative research. The determination of the informants in this study was obtained by purposive sampling. The informants are community leaders and traditional leaders who are key informants. The results show that the opportunity for Wakatobi Regency to become a cultural tourism destination can be opened, because it is supported by the exoticism of local communities with their cultural diversity. The strategy that can be prioritized in the development of Wakatobi village tourism is the diversification of cultural attractions that are organized through institutions or Tourism Awareness Groups initiated by the community and funded by the local government and acting as an active facilitator. It seems that the political will and political commitment of leaders to maximize local government efforts need to be supported by tourism stakeholders from the government, private sector and the wider community, this is a weakness that needs to be covered so that the strategy in developing Community Base Tourism (CBT) tourism in Wakatobi provides a diversification of attractions. tour which is actually quite interesting to witness.
\end{abstract}

Keywords: Strategy, Diversification; Cultural Attractions; Tourism Development

\begin{abstract}
Abstrak
Penelitian ini bertujuan untuk mengetahui dan menganalisa Strategi Diversifikasi Atraksi Budaya Dalam Mendukung Pengembangan Wisata Desa Wakatobi. Metode penelitian ini adalah penelitian kualitatif. Penentuan informan penelitian ini diperoleh secara Purposive sampling. Adapun informan yaitu tokoh masyarakat dan tokoh adat yang merupakan informan kunci. Hasil penelitian menunjukkan peluang kabupaten wakatobi menjadi destinasi wisata budaya dapat terbuka, karena didukung oleh eksotisme komunitas lokal dengan keberagaman budaya yang mereka miliki. Strategi yang dapat diprioritas dapat dalam pengembangan wisata desa Wakatobi adalah diversifikasi atraksi budaya yang terorganisasi melalui kelembagaan atau Kelompok Sadar Wisata yang diprakarsai masyarakat dan didanai oleh pemerintah daerah serta berperan sebagai fasilitator yang aktif. Tampaknya political will dan political comitment pemimpin untuk memaksimalkan upaya pemerintah daerah perlu di dukung oleh stekholder pariwisata dari pihak jajaran pemerintah, swasta dan masyarakat luas hal merupakan kelemahan yang perlu ditutupi agar strategi dalam pengembangan wisata Community Base Tourism (CBT) di Wakatobi menyajikan adanya diversifikasi atraksi wisata yang sesungguhnya cukup menarik untuk disaksikan.
\end{abstract}

Kata Kunci: Strategi; Diversifikasi; Atraksi Budaya; Pengembangan Pariwisata

Link DOI : $\underline{\text { http://dx.doi.org/10.31314/pjia.9.1.25-33.2020 }}$ 


\section{PENDAHULUAN}

Bagi Indonesia peranan pariwisata semakin penting, terutama setelah melemahnya peranan minyak dan gas. Apalagi kunjungan wisatawan mancanegara menunjukkan trend yang meningkat dalam beberapa dasawarsa. Saat ini, pemerintah fokus menggarap wisatawan asing. Selama tahun 2010 jumlah wisatawan mancanegara ke Indonesia mencapai 7,002 juta orang atau naik $10,74 \%$ dibandingkan dengan jumlah wisatawan mancanegara pada tahun 2009.

World Travel Tourism Council (WTTC) menyatakan disadari atau tidak, kepariwisataan dunia telah menjelma sebagai sebuah "mega Industri", dan diperkirakan akan menjadi salah satu penggerak utama perekonomian abad 21 . WTTC bahkan telah memprediksi industri pariwisata akan menggerakkan mobilitas wisatawan di seluruh dunia pada dasawarsa mendatang (Scott et al., 2016).

Data Kementerian Pariwisata menunjukkan tahun 2012, jumlah wisatawan mancanegara yang berkunjung ke Indonesia berjumlah 8 juta tahun 2013 meningkat menjadi 8.802 .129 orang. Ini menunjukkan pertumbuhan sekitar 9,42 persen, dan pada tahun 2014 jumlah wisatawan mancanegara mencapai 9.435.411 orang. Staff ahli Menteri Pariwisata Han Wintoro (Kompas, 14 November 2015), menuturkan, tahun ini wisatawan mancanegara yang berkunjung ke Indonesia ditargetkan menjadi 10 juta orang. Diharapkan kedepan, wisatawan mancanegara yang berkunjung ke Indonesia tahun 2019 mencapai 20 juta orang.

Salah satu kawasan yang meningkatkan tingkat pertumbuhan terbesar adalah negara-negara di Asia, termasuk Indonesia. Sudah barang tentu peningkatan jumlah wisatawan mancanegara yang mengunjungi ke Indonesia memberi penilaian positif terhadap devisa Negara. Bagindo, Model Bisnis Ekowisata dapat menjadi segment unggulan jika dikelola secara profesional dengan memanfaatkan kapasitas sumber daya lokal (Imran, 2012; Bagindo et al., 2016).

Meningkatnya destinasi dan investasi, pariwisata telah menjadi faktor kunci dalam pendapatan ekspor, penciptaan lapangan kerja, juga pengembangan usaha dan infrastruktur, yang menyebabkan pariwisata mengalami eksplanasi dan diversifikasi berkelanjutan (Cernat \& Gourdon, 2012). Saat ini, pariwisata menjadi salah satu sektor ekonomi terbesar dan ke empat pertumbuhannya di dunia. Pencinta penyu, dapat menyaksikannya di Pulau Rundunta, sebelah utara Pulau Kaledupa.

Wisata etnik pun cukup menarik di daerah ini dengan keberadaan beberapa komunitas lokal yang memiliki beragam budaya upacara tradisional,terutama tari tradisional berkembang di pulau WangiWangi,Kalidupa, Tomia dan Binongko. Tari tradisional ini selalu di pertunjukkan ketika pemerintah menerima tamu,juga di pertunjukkan pada wisatawan.

Penelitian terdahulu Supriadi (2016) menunjukkan pengembangan pariwasata belum memaksimalkan budaya yang unik selain keindahan alam. Selain itu penelitian Ernawati \& Mahmudah (2016) juga menunjukkan kurangnya upaya memaksimalkan potensi budaya dalam pengembangan pariwisata.

Dari penelitian terdahulu memiliki kelemahan dalam penelusuran Diversifikasi Atraksi Budaya oleh karena itu penelitian ini bertujuan untuk mengetahui dan menganalisa Strategi Diversifikasi Atraksi Budaya Dalam Mendukung Pengembangan Wisata Desa 
Wakatobi.

\section{METODE PENELITIAN}

Metode penelitian yang digunakan adalah penelitian kualitatif karena itu peranan peneliti sebagai instrumen penelitian sangat penting. Dalam mengumpulkan data, peneliti menggunakan model multivokal dialogis, dimana peneliti dapat melakukan wawancara secara bebas. Selain itu, peneliti juga menggunakan teknik observasi dan dokumentasi.

Penentuan informan penelitian ini yaitu diperoleh secara Purposive sampling yaitu tokoh masyarakat dan tokoh adat yang merupakan informan kunci atau informan utama dalam mendapatkan data dalam rangka menyelesaikan penelitian ini. Disamping itu peneliti juga mentukan informan pendukung seperti instanstasi terkait, sanggar tari yang bertujuan untuk menambah data dan informasi yang di butuhkan. Melalui wawancara kualitatif yang mendalam (indepth-interview), peneliti mampu memperoleh data yang spesifik mengenai fokus penelitian dalam hal ini terkait dengan destinasi desa wisata di Wakatobi. Analisis data yaitu reduksi data, penyajian data dan penarikan kesimpulan.

\section{HASIL DAN PEMBAHASAN \\ Diversifikasi Atraksi Budaya}

Berdasarkan hasil observasi dan wawancara pada menunjukkan ritual yang dilakukan di destinasi desa wisata di Wakatobi bagi masyarakat tradisional, sesungguhnya merefleksikan kesadaran, bahwa manusia sebagai makhluk hidup sangat memiliki keterbatasan dalam menyikapi dan memahami peristiwaperistiwa makrokosmos. Dalam hal ini manusia menunjukkan ketidakberdayaan dalam menghadapi makhluk-makhluk supranatural yang lebih digdaya. Copyright @ 2020 , Publik (Jurnal Ilmu Administrasi), ISSN: 2301-573X (Print), ISSN: 2581-2084 (Online)
Kabuenga pada masyarakat WangiWangi Wakatobi adalah contoh dari pemahaman tersebut. Sehingga harus dilaksanakan setiap tahun saat perayaan Idul Fitri, dan karena itu pula ritual tersebut menjadi tradisi budaya. Sebagai tradisi Kabuenga harus dijaga dan diwariskan secara turun temurun sampai dari tiang menyangga berupa bambu yang panjangnya dapat mecapai 10 meter, jarak ayunan mencapai 5 meter. Mereka yang duduk pada alas ayunan,akan diayun dengan cara menarik bentangan tali yang dilakukan oleh dua orang. Melalui kekuatan laki-laki yang kuat, mereka yang diayun akan melayang dnegan ayunan. Cukup tinggi, sehingga mendebarkan, tetapi sorak-sorai peserta ritual yang cukup banyak, menjadikan acara tersebut menyenangkan dan menggembirakan.

Kegembiraan itu sebenarnya terjadi karena keberhasilan yang telah dicapai masyarakat dalam kegiatan mereka dalam mencari nafkah, sehingga itu patut disyukuri. Tradidi Kabuenga pun tidak seluruhnya sakral, melainkan pada bagianbagian tertentu dari ritual bersifat profan,dimana peserta dapat tertawa,bercanda gurau dan bergembira ria.

Tradisi Kabuenga yang menggambaran suasana kegembiraan tersebut, juga karena fungsi Kabuenga sejak zaman dahulu sebagai media penyambutan tamu. Acara penyambutan tamu ini menjadi kebiasaan masyarakat madati dan Wanci yang menjemput kedatangan pejabat Walio, kerajaan buton yang bertugas didaerah ini dengan maksud pejabat tersebut merasakan kehangatan yang tercipta dalam suasana bersahabat dengan masyarakat yang di datangi. Dengan kesan dalam penjemputan itu, menyebabkan pejabat kerajaan tersebut betah tinggal di tempat tugasnya.

Sakralitas tradisi Kabuenga tampak ketika, ritual tersebut akan dimulai, dimana 
tetua adat melalui prosesi dengan doa oleh dua orang tetua adat yang memanjatkan doa untuk meminta keselamatan dan keberkahan kepada sang pencipta Allah SWT yang menciptakan alam semesta ini. Tetua adat membacakan doa tolak bala untuk menjauhkan masyarakat dari marah bahaya.

Tradisi Kabuenga juga menjadi ajang untuk mencari jodoh. Karena itu,dimana pada setiap rumah yang mempunyai anak gadis untuk mempersiapkan makanan dan minuman tradisional yang akan disuguhkan kepada para tamu yang hadir. Setelah selesai acara suguhan makakan dan minuman selesai dilaksanakan, kemudian dilanjutkan dengan acara atraksi budaya seperti mansa'a (pencak silat) dan pada sore dan malam hari di pertunjukkan tari tradisional.

Mansa'a pada dasarnya adalah permainan pencak silat, yang keberadaannya di Wakatobi merupakan difusi unsur budaya Melayu, pada zaman dahulu, orang Wakatobil adalah kelompok masyarakat yang memang banyak mendapatkan pengaruh dari luar, sebagai akibat kawasan Wakatobi yang menjadi jalur pelayanan baik yang melalui perairan dari arah timur,maupun dari arah barat.

Pencak silat tergolong olahraga beladiri dengan tujuan untuk mempertahankan diri, mengelak, berkelit maupun menyerang agar dapat melumpuhkan lawan, baik dengan tangan kosong,maupun dengan menggunakan senjata tajam. Para murid biasanya berguru pada seorang guru pencak silat disebuah pedepokan,dimana mereka ditempah suatu keterampilan agar dapat menguasai jurus andalan yang menjadi senjata pamungkas, Bahkan dalam padepokan itu, para murid biasanya juga mendalami ilmu kanuragan lainnya, termasuk ditempah untuk memiliki tenaga dalam yang memungkinkan seorang murid menjadi pendekar.

Sebagai hasil kebudayaan asli Indonesia, pencak silat sudah seharusnya di lestarikan dan dikembangkan sebagai sebuah seni bela diri yang dapat dipertontonkan sebagai suatu atraksi wisata. Apalagi masyarakat Wangi-Wangi menyelenggarakan Mansa'a usai acaraacara resmi, sesudah shalat Idul Fitri, juga pada acara pernikahan, sunatan massal, atau bahkan dlakukan saat pesta rakyat.

Kabuenga sebagai ajang pencarian jodoh dilatari oleh cerita rakyat yang begitu terkenal bagi masyarakat WangiWangi sebagimana dituturkan dalam cerita rakyat, yakni cerita La Lili Alamu, Putra Mahkota Kerajaan Kambode di Pulau Kapota, yang dilatar belakangi tradisi masyarakat Kepulauan Wakatobi ini. Sebagai pria yang telah beranjak dewasa, La Lili Alamu merasa bahwa telah tiba waktunya bagi seorang wanita untuk bersanding dengan seorang gadis. Niatnya ini disampaikan kepada Ayahandanya Raja Kambode.

Kepada ayahnya, La Lili Alamu menyebut "Wa Siogena",nama seorang gadis yang datang dari kalangan rakyat jelata. Nama yang juga ada di hatinya meski slama ini tidak banyak yang mengetahuinya. Bayangan Wa Siogena selalu ada di dalam pikiran, bahkan hadir di dalam mimpi-mimpi putra sang raja. Mengetahui bahwa yang ingin di pinang anaknya adalah seorang gadis dari kalangan rakyat jelata, memuncaklah kemarahan sang Raja, tentu saja ayah La Lili Alamu menolak mentah-mentah rencana ini.

Kekecewaan yang begitu mendalam menyelimuti hati La Lili Alamu, tercetuslah niatnya untuk merantau kesuatu tempat yang jauh. Sang ibu merestui, sang ayah pun merelakannya dengan harapan 


\section{Available Online at http://journal.umgo.ac.id/index.php/Publik \\ Publik (Jurnal Ilmu Administrasi) Vol 9 (1), Juni 2020}

putranya akan melupakan pujaan hatinya. Wa Sogena. Tahun Demi Tahun telah berlalu, berbagai tempat pun telah disinggahi oleh La Lili Alamu, banyak sudah wanita yang dikenalnya, namun Wa Siogena tetap pada pilihannya. Bayangbayang gadis kampung ini selalu tersimpan dalam ingatan dan sanubarinya. Sepulang La Lili Alamu dari perantauan, Raja Kambode mengadakan sayembara untuk mencari pasangan hidup bagi anaknya. Dikumpulkanlah gadis-gadis bangsawan dari penjuru negeri. Raja Kambude pun bertitah:

"Putraku akan memilih sarung leja buatan tangan kalian yang semuanya akan dikumpulkan di sebuah ayunan. Wanita yang memintai sarung leja yang terpilih oleh anakku, maka ialah yang akan menjadi istrinya".

Sampai disini akhir cerita dari rakyat Wakatobi ini, dan rasanya sudah biasa ditebak, La Lili Alamu memilih sarung buatan Wa Siogena yang tertindis dibagian paling bawah tumpukan sarung-sarung leja yang semuanya tergantung di sebuah kain yang terikat bakayunan. Raja kambode pun tak dapat mengelak lagi, meskipun bukan keturunan bangsawan, jodoh sudah ditentukan. Maka, menikahlah La Lili Alamu dnegan Wa Siogena, pujaan hatinya sejak dulu. Banyaknya pemuda yang merantau keluar daerah dalam waktu yang lama menyebabkan kecil kemungkinan bagi seorang pemuda Wakatobi untuk kenal lebih dekat dengan para gadis yang berasal dari kampung halamannya. Untuk itu diselenggarakanlah 'Kabuenga', sebuah cara pencarian jodoh dikalangan masyarakat Wakatobi.

Tradisi yang sudah berlangsung secara turun temurun sejak masa keemasan kerajaan dan kesultanan. Buton ini kerap dikunjungi para wisatawan mancanegara. Meski di zaman sekarang para putra dan putri lebih suka memakai caranya sendiri Copyright @ 2020, Publik (Jurnal Ilmu Administrasi), ISSN: 2301-573X (Print), ISSN: 2581-2084 (Online) dalam menentukan pangan hidupnya, 'Kabuenga' masih diadakan setiap tahun sebagai bagian dari upaya mempertahankan budaya asli masyarakat kepulauan wakatobi yang adalah bagian dari kesultanan buton dimasa lampau.

Pada saat ini, kabuenga masih secara konsisten diselenggarakan, tetapi ada unsur dalam upacara yang berubah. Perubahan terlihat pada penggunaan sarung Leja, sarung pengantin khas masyarakat setempat. Wanita-Wanita perserta upacara berkumpul dilapangan dengan beragam makanan yang nantinya akan diberikan kepada pemuda desa. Hidangan laut berupa lobster, ikan, dan kepiting yang diolah dengan bumbu khas daerah semuanya telah dipersiapkan dan dibawah dari rumah mereka masing-masing. Tak lupa juga 'kasuami',kuliner khas berbahan dasar singkong dan sudah terkenal sebagai makanan alternatif pengganti nasi bagi masyarakat setempat, juga mereka bawa. Demikian juga 'kasia,i pepe', berbeda dengan 'kasuami'yang disajikan dengan bentuk tumpeng-tumpeng yang kecil, kuliner yang satu ini berbentuk lonjong seperti lemper dan berisikan abon yang terbuat dari daging ikan.

Dalam acara ini para wanita yang semuanya mengenakan busana khas Wolio, duduk berjejer mengitari sebuah ayunan yang telah disediakan sebelumnya. Suatu hal yang menarik,konde yang mereka kenakan dikepala menunjukan status mereka. Konde berbentuk bulat membedakan mereka dengan konde yang dipakai beberapa wanita wolio lain yang bentuknya runcig memanjang kebelakang dan berkucir. Konde berbentuk bulat menandakan bahwa pemakainya masih gadis, sedangkan yang dibentuk runcing menandakan pemakainya telah bersuami. Selain itu para wanita ini tak lupa pula membawa serta keluarga beserta kerabat untuk menemani mereka 'menawarkan 
makanan'. Seketika itu pula sang pemuda memilih gadis yang memikat hatinya. Pemuda ini pun akan berjalan mengitari lingkaran, bila tertarik kepada si gadis maka pemuda tadi akan menghampirinya dan membeli makanan yang dijajakannya. Sambil membalas pantun berbahasa daerah proses jual beli makanan pun berlangsung. Setelahnya kedua paangan ini berjalan ke tengah lingkaran menuju ayunan.

\section{Strategi Atraksi Budaya Pada Community Base Tourism (CBT)}

Dari hasil penelitian menunjukkan adanya strategi dalam bentuk Atraksi Budaya Pada Community Base Tourism (CBT) hal ini terlihat dari ritual seperti 'Kabuenga', sebuah cara pencarian jodoh dikalangan masyarakat Wakatobi yang dipelihara, Pencak silat, dan tari hal menujukkan Community Base Tourism (CBT) adalah strategi yang paling tepat di Kabupaten Wakatobi menurut Rahayu (2016) melihat Pengembangan Community Based Tourism Sebagai Strategi Pemberdayaan Masyarakat terbagi dua yaitu dengan merancang berbagai produk wisata, seperti dan meningkatkan kemampuan, ketrampilan dan kompetensi masyarakat dalam mengelola pariwisata, karena dalam CBT masyarakatlah yang mempunyai peran utama hal ini juga dijelaskan dalam penelitian Novaria \& Rohimah (2017).

Pentingnya pengembangan desa wisata menjadi wisata alternatif maupun wisata minat khusus (special interest tourisms) yang memiliki peluang untuk berfungsi sebagai agrowisata, ekowisata, geowisata, wisata kuliner, wisata spritiual, wisata kesehatan dan lain-lain. Dengan demikian, desa wisata dapat menjadi tujuan wisata sesuai motivasi wisatawan untuk berwisata di Wakatobi. Dengan optimalisasi pemanfaatan wilayah dimaksudkan untuk mengoptimalkan potensi wisata. Community Base Tourism (CBT) Wakatobi menyajikan adanya diversifikasi atraksi budaya dan wisata yang sesungguhnya cukup menarik untuk disaksikan.

Peluang kabupaten wakatobi menjadi destinasi wisata budaya dapat terbuka, karena didukung oleh eksotisme komunitas lokal dengan keberagaman budaya yang mereka miliki. Tampaknya political will dan political comitment pemimpin tegak yang begitu tekad untuk melibatkan pemerintah daerah, perlu di dukung oleh stekholder pariwisata dari pihak jajaran pemerintah, swasta dan masyarakat luas.

Dalam hubungannya dengan penyeimbangan pariwisata desa, perlu mempertimbangkan hal-hal sebagai berikut: (1). Membentuk kelompok sadar wisata pada tingkat desa potensial dengan pertimbangan bhawa, masyarakat di desa itu sendiri yang banyak mengetahui sumber daya yang dimiliki, baik itu Ritual adat, tari dan beberapanya yang layak dikembangkan sebagai atraksi wisata, Kelompok sadar didirikan warga desa yang anggotanya terdiri dari para pelaku kepariwisataan yang memiliki kepedulian dan tanggung jawab serta berperan sebagai penggerak untuk menciptakan iklim yang kondusif bagi berkembangnya kepariwisataan di wilayah desa mereka serta mewujudkan. (2). Kelompok sadar wisata harus memliki komitmen untuk mengealisasikan sapta pesona pariwisata: aman, tertip,bersih,sejuk, indah, ramah, dan kenangan hal ini penting untuk meningkatkan kesadaran tanggung jawab bersama dalam mengembangkan pariwisata desa.

Kelompok sadar wisata merupakan kelompok yang tumbuh atas inisiatif dan kemauan serta kesadaran masyarakat sendiri guna ikut berpartisipasi aktif 
memelihara dan melestarikan berbagai obyek dan daya tarik wisata dalam rangka meningkatkan

pembangunan kepariwisataan di daerah. Dapat dipahami bahwa pembangunan Kepariwisataan merupakan kegiatan lintas sektoral karena itu kesuksesan pembangunan kepariwisataan Nasional dan daerah sangat ditentukan oleh adanya dukungan serta partisipasi aktif seluruh lapisan masyarakat, baik dari unsur pemerintah dan juga pihak swasta.

Strategi menghubungkan atau mengaitkan kekuatan atau keunggulan organisasi dengan peluang dari lingkungannya yang penting dalam pengembangan pariwisata (Gustavo, 2013). Dalam penelitian ini kekuatan organisasi adalah komitmen pemimpin dan agenda pemerintah daerah dalam mengembangkan wisata desa di Wakatobi.

Salah satu strategi yang dinilai tepat adalah Community Base Tourism (CBT) Wakatobi menyajikan adanya diversifikasi atraksi budaya mengingat budaya adalah peluang untuk diesploitasi sebagai bagian dari agenda pariwisata. Hal ini sejalan dalam penelitian Chumsri et al (2015) yang mengatakan bahwa manajemen yang sukses dalam pariwisata berkelanjutan harus dilakukan dalam bentuk kegiatan masyarakat.

Agenda Community Base Tourism (CBT) tidak hanya berhenti pada terselenggaranya kegiatan namun outcome dari kegiatan tersebut. Upaya ini dapat dimulai dari diversifikasi budaya yang potensi mengakar pada masyarakat sangat besar sehingga menjadi bagian yang dapat dieksploitasi dalamn pengembangan pariwisata secara berkelanjutan hal ini sejalan dengan rekomendasi dari penelitian Sharma (2015) pengembangan pendidikan pada masyarakat tentang pentingnya pariwisata yang dimanfaatkan dengan mengeksploitasi keberhasilan dan kesuksesan yang didapat sekarang, sekaligus menyelidiki adanya peluangpeluang baru. Penelitian terdahulu Syahrial \& Badollahi (2020) juga menunjukkan besarnya peran CBT dalam pengembangan pariwisata yang berbasispartisipasi masyarakat.

Selanjutnya Sumantra et al (2015) mengemukakan paradigma baru dalam pembangunan diakomodasikan dalam pembangunan pariwisata yang mengedepankan pemberdayaan masyarakat dan mengembangkan ekonomi kerakyatan serta pelestarian lingkungan. Dengan cara ini, pengembangan, kegiatan kepariwisataan akan dapat dilanjutkan dengan melanjutkan keberlanjutan dengan pelestarian, penjagaan dan pemulihan daya dukung serta kepekaan terhadap hubungan lingkungan alam, sosial dan budaya. Untuk itu diperlukan kepedulian masyarakat.

Tari tradisi penting dalam kepariwisataan Sebagai upaya mensinergikan dengan pembelanjaan wisata lain, seperti wisata alam untuk menambah waktu singgah wisatawan yang otomatis akan membelanjakan uangnya lebih banyak.

Perlunya pengembangan wisata pedesaan, juga berdasarkan alasan itu; (1) menarik minat wisatawan Saat menarik memilih wisatawan yang berorientasi pada tantangan, tantangan, fantasi, nostalgia dan pengalaman eksotik, (2) mengalihkan minat para wisatawan memberikan prioritas pada upaya-upaya pemberdayaan dan peningkatan ekonomi masyarakat lokal serta, (3) Hubungi wisatawan untuk mengaktualisasi dan mengembangkan diri melalui bentuk-bentuk interaksi yang dibuat dengan masyarakat lokal. Community Base Tourism (CBT) mendukung optimalisasi pemanfaatan wilayah yang dimaksudkan untuk mengoptimalkan potensi wisata. Community Base Tourism (CBT) Copyright (c) 2020, Publik (Jurnal Ilmu Administrasi), ISSN: 2301-573X (Print), ISSN: 2581-2084 (Online) 
Wakatobi menyajikan adanya diversifikasi atraksi budaya dan wisata yang sesungguhnya cukup menarik untuk disaksikan dan mendukung dalam pengembangan pariwisata.

\section{PENUTUP}

\section{Kesimpulan}

Berdasarkan uraian di atas diperoleh kesimpulan bahwa ada strategi dalam bentuk atraksi budaya pada Community Base Tourism (CBT), hal ini terlihat dari ritual seperti 'Kabuenga', sebuah cara pencarian jodoh dikalangan masyarakat Wakatobi yang dipelihara, Pencak silat, dan tari hal menujukkan Community Base Tourism (CBT) adalah strategi yang paling tepat. Community Base Tourism (CBT) Wakatobi menyajikan adanya diversifikasi atraksi wisata yang sesungguhnya cukup menarik untuk disaksikan.

\section{Saran}

Pemberdayaan yang diberikan pemerintah setempat tidak cukup dengan adanya political will pemerintah setempat namun memerlukan bentuk-bentuk interaksi yang dibuat masyarakat lokal dan stakeholder terkait. Strategi yang dapat diprioritas dapat dalam pengembangan wisata desa Wakatobi adalah diversifikasi atraksi budaya yang terorganisasi melalui kelembagaan atau Kelompok Sadar Wisata yang diprakarsai masyarakat dan didanai oleh pemerintah daerah serta berperan sebagai fasilitator.

\section{DAFTAR PUSTAKA}

Bagindo, M. P., Sanim, B., \& Saptono, T. (2016). Model Bisnis Ekowisata di Taman Nasional Laut Bunaken dengan Pendekatan Business Model Canvas. MANAJEMEN IKM: Jurnal Manajemen Pengembangan Industri Kecil Menengah, 11(1), 80-88.
Cernat, L., \& Gourdon, J. (2012). Paths to success: Benchmarking crosscountry sustainable tourism. Tourism management, 33(5), 1044-1056.

Chumsri, P., Chanin, O., \& Sriprasert, P. (2015). Guidelines on Developing Community Base Tourism to Sustainable Management of Tourist Attractions. Journal of Economics, Business and Management, 3(6), 653-655.

Ernawati, H., \& Mahmudah, S. A. (2016). Strategi Pengembangan Desa Wisata Seni \& Kerajinan Kasongan, Bangunjiwo, Bantul, Yogyakarta. Kepariwisataan: Jurnal Ilmiah, 10(3).

Gustavo, N. (2013). Marketing management trends in tourism and hospitality industry: facing the $21 \mathrm{st}$ century environment. International Journal of Marketing Studies, 5(3), 13.

Imran, A. N. (2012). Identifikasi Kapasitas Komunitas Lokal daalam Pemanfaatan Potensi Ekowisata Bagi Pengembangan Ekowisata di Kawah Cibuni. Journal of Regional and City Planning, 23(2), 85-102.

Novaria, R., \& Rohimah, A. (2017). Pengembangan Community Based Tourism Sebagai Strategi Pemberdayaan Masyarakat Dan Pemasaran Pariwisata Di Wonosalam Kabupaten Jombang. In Prosiding Seminar dan Call For Paper 20-21 Oktober 2017. Fakultas Ilmu Sosial dan Ilmu Politik Universitas Muhammadiyah Sidoarjo.

Rahayu, S., Dewi, U., \& Fitriana, K. N. (2016). Pengembangan Community Based Tourism sebagai Strategi 
Pemberdayaan ekonomi Masyarakat di Kabupaten Kulon Progo, Daerah Istimewa Yogyakarta. Jurnal Penelitian Humaniora UNY, 21(1), 124561.

Scott, D., Hall, C. M., \& Gössling, S. (2016). A review of the IPCC Fifth Assessment and implications for tourism sector climate resilience and decarbonization. Journal of Sustainable Tourism, 24(1), 8-30.

Sharma, A. (2015). Educational tourism: strategy for sustainable tourism development with reference of Hadauti and Shekhawati regions of Rajasthan, India. Journal of Business Economics and Information Technology, 11(4), 1-12.

Syahrial, S., \& Badollahi, M. Z. (2020). Development of a Community-Based Marine Tourism Attraction in the Samboang Beach in Bulukumba Regency. Journal Bisecoman, 1(2), 1-9.

Sumantra, I. K., Yuesti, A., \& Sudiana, A. K. (2015). Pengembangan model agrowisata salak berbasis masyarakat di Desa Sibetan. Jurnal Bakti Saraswati (JBS), 4(2).

Supriadi, B. (2016). Pengembangan Ekowisata Pantai Sebagai Diversifikasi Mata Pencaharian. Jurnal Pariwisata Pesona, 1(1). 